\title{
Cystoid Macular Edema after Complicated Cataract Surgery Resolved by an Intravitreal Dexamethasone 0.7-mg Implant
}

\author{
Linda M. Meyer Carl-Ludwig Schönfeld \\ Herzog Carl Theodor Eye Clinic, Munich, Germany
}

\section{Key Words}

Cystoid macular edema $\cdot$ Irvine-Gass syndrome $\cdot$ Dexamethasone $0.7 \mathrm{mg} \cdot$ Ozurdex ${ }^{\circledR}$

\begin{abstract}
Purpose: To report the effective treatment of cystoid macular edema (CME) following complicated cataract surgery (resulting in Irvine-Gass syndrome) with a dexamethasone 0.7-mg (Ozurdex ${ }^{\circledR}$ ) intravitreal implant.

Methods: An interventional case report with optical coherence tomography (OCT) scans. Results: An 83-year-old Caucasian woman was suffering from CME following complicated cataract surgery on her left eye. She had undergone 3 intravitreal injections of dexamethasone $0.4 \mathrm{mg}$ in the 3 months following the surgery without any improvement of visual function. Seven months after the cataract surgery, she received a single intravitreal injection of dexamethasone $0.7 \mathrm{mg}$ (Ozurdex). Four weeks following the injection, her best-corrected visual acuity improved from 0.3 to 0.8 . CME resolved with a reduction of central retinal thickness from $393 \mu \mathrm{m}$ pre-Ozurdex injection to $212 \mu \mathrm{m}$ postOzurdex injection, as measured by OCT scan.

Conclusion: Dexamethasone $0.7 \mathrm{mg}$ (Ozurdex) has proven to be an effective treatment option in retinal vein occlusion and non-infectious uveitis. It can also be considered as off-label treatment in Irvine-Gass syndrome.
\end{abstract}

\section{Introduction}

Irvine-Gass syndrome, which describes vision loss after cataract surgery due to cystoid macular edema (CME), is still recognized as one of the most common causes of poor visual outcome following cataract surgery $[1,2]$. Despite treatment options for IrvineGass syndrome which include non-steroidal anti-inflammatory drugs, corticosteroids and 
acetazolamide, and new fields of clinical research including the use of anti-vascular endothelial growth factor agents, resistant cases of macular edema are common $[3,4]$.

Corticosteroids are potent anti-inflammatory agents that can counteract many of the pathological processes thought to play a role in the development of postoperative CME. Recently, a sustained-release dexamethasone implant $\left(\mathrm{Ozurdex}^{\circledR}\right)$ has become available for the treatment of patients suffering from CME due to retinal vein occlusion and noninfectious uveitis [5].

We report a case of CME resolution and significant improvement of visual function following the intravitreal injection of dexamethasone $0.7 \mathrm{mg}$ in a patient with Irvine-Gass syndrome even after previous intravitreal therapy with dexamethasone $0.4 \mathrm{mg}$ had been repeatedly unsuccessful.

\section{Case Report}

An 83-year-old Caucasian woman developed CME following complicated cataract surgery on her left eye in 2010 (fig. 1). She had undergone 3 intravitreal injections of dexamethasone $0.4 \mathrm{mg}$ in the following 3 months without any improvement in visual acuity. Seven months after the cataract surgery, she presented for the first time at our clinic and received a single intravitreal injection of dexamethasone $0.7 \mathrm{mg}$ (Ozurdex) as off-label treatment. Four weeks following the injection, her best-corrected visual acuity (BCVA) improved from 0.3 to 0.8 . The CME resolved with a reduction of central retinal thickness from $393 \mu \mathrm{m}$ pre-Ozurdex injection to $212 \mu \mathrm{m}$ post-Ozurdex injection, as measured by optical coherence tomography (OCT) scan (fig. 2). Her condition has been stable for at least 3 months now, as seen on the last examination, with BCVA 0.8 and resolved macular edema (fig. 3$)$ in the treated eye.

\section{Discussion}

Current evidence suggests that the dexamethasone 0.7-mg implant (Ozurdex) is a favorable treatment option in patients with CME and vision loss due to retinal vein occlusion and non-infectious uveitis [6,7]. In accordance with the case report presented here, a subgroup analysis of a clinical phase II study indicated that dexamethasone $0.7 \mathrm{mg}$ might also be effective in patients suffering from Irvine-Gass syndrome following cataract surgery [8].

However, it is unknown whether the dexamethasone $0.7-\mathrm{mg}$ implant could even effectively reduce CME in already pre-treated eyes that were refractory to previous intravitreous dexamethasone injections. Our case report indicates that Ozurdex effectively restores visual function and reduces CME in Irvine-Gass syndrome even though previously applied intravitreous treatment with 3 dexamethasone injections was unsuccessful. Similar to the results from Williams et al. [8], who reported a considerable functional improvement after treating Irvine-Gass patients with dexamethasone $0.7 \mathrm{mg}$, our patient improved from BCVA 0.3 pre-Ozurdex injection to BCVA 0.8 post-Ozurdex injection.

A possible explanation for the inefficiency of previous intravitreal dexamethasone injections in the presented case could be the short half-life of unbound dexamethasone in the vitreous cavity [9]. This problem can be overcome by the currently available sustained-release dexamethasone implant. 
In conclusion, the dexamethasone implant (Ozurdex) might be an effective treatment option not only in retinal vein occlusion and non-infectious uveitis but can also be considered as off-label treatment in Irvine-Gass syndrome.

\section{Disclosure Statement}

The authors have no conflicts of interest to declare.

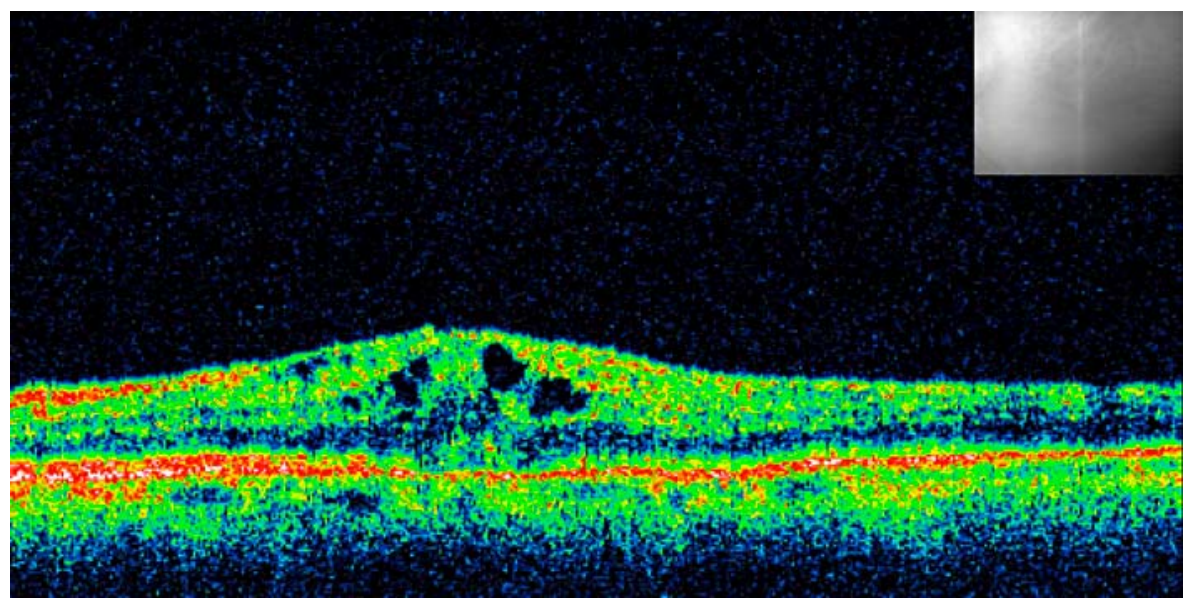

Fig. 1. OCT scan of CME following complicated cataract surgery. The infrared picture shows retinal localization. CME was refractory to treatment with 3 intravitreal injections of dexamethasone $0.4 \mathrm{mg}$. Central retinal thickness was $393 \mu \mathrm{m}$.

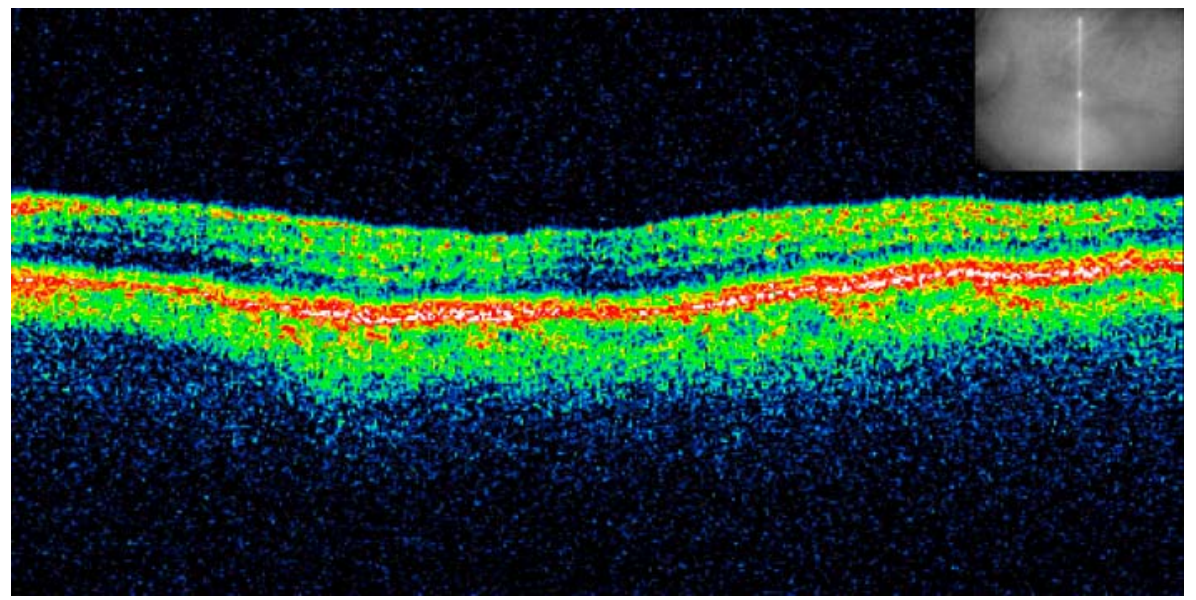

Fig. 2. Resolved macular edema 4 weeks following an intravitreal injection of a dexamethasone $0.7-m g$ implant (Ozurdex). The infrared picture shows retinal localization. Central retinal thickness was 212 $\mu \mathrm{m}$. 


\section{Case Reports in Ophthalmology}

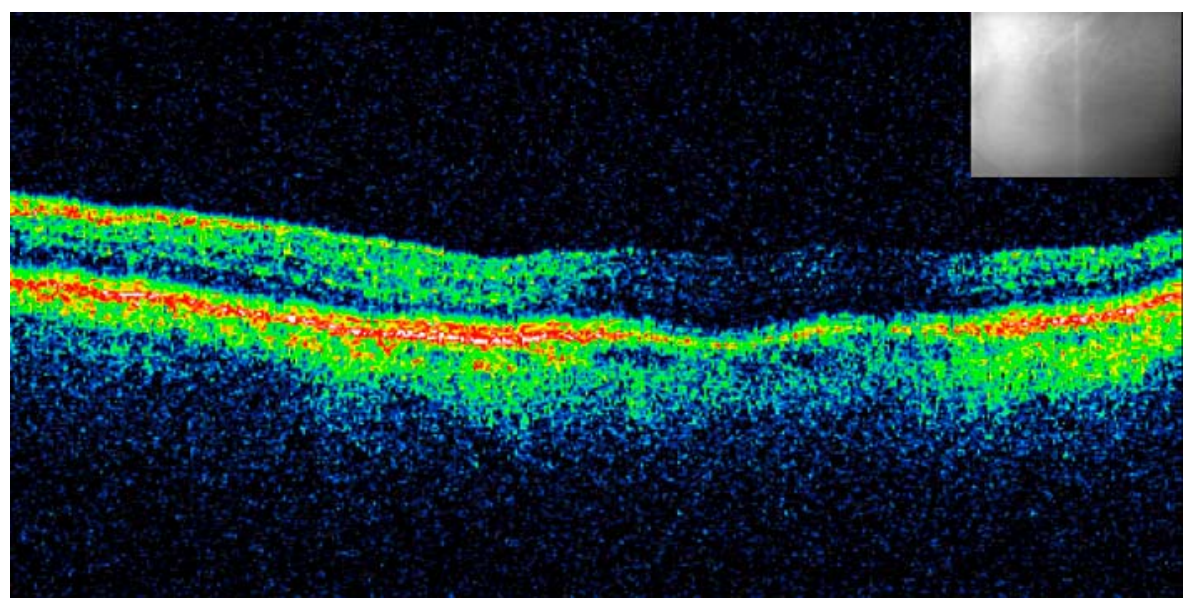

Fig. 3. Follow-up examination 120 days after Ozurdex injection. The infrared picture shows retinal localization. Central retinal thickness was $210 \mu \mathrm{m}$.

\section{References}

1 Arevalo JF, Maia M, Garcia-Amaris RA, Roca JA, Sanchez JG, Berrocal MH, Wu L; Pan-American Collaborative Retina Study Group: Intravitreal bevacizumab for refractory pseudophakic cystoid macular edema: the Pan-American Collaborative Retina Study Group results. Ophthalmology 2009;116:1481-1487.

2 Drolsum L, Haaskjold E: Causes of decreased visual acuity after cataract extraction. J Cataract Refract Surg 1995;21:59-63.

-3 Shelsta HN, Jampol LM: Pharmacologic therapy of pseudophakic cystoid macular edema: 2010 update. Retina 2011;31:4-12.

-4 Sivaprasad S, Bunce C, Wormland R: Non-steroidal anti-inflammatory agents for cystoid macular edema following cataract surgery: a systematic review. Br J Ophthalmol 2005;89:1420-1422.

5 Herrero-Vanell R, Cardillo JA, Kuppermann BD: Clinical applications for the sustained-release dexamethasone implant for treatment of macular edema. Clin Ophthalmol 2011;5:139-146.

-6 Haller JA, Bandello F, Belfort R Jr, et al; OZURDEX GENEVA Study Group: Randomized, sham-controlled trial of dexamethasone intravitreal implant in patients with macular edema due to retinal vein occlusion. Ophthalmology 2010;117:1134-1146.

7 Lowder C, Belfort R, Lightman S, Foster CS, Robinson MR, Schiffman RM, Li XY, Cui H, Whitcup SM; for the Ozurdex HURON Study Group: Dexamethasone intravitreal implant for noninfectious intermediate or posterior uveitis. Arch Ophthalmol 2011;129:545-553.

-8 Williams GA, Haller JA, Kuppermann BD, Blumenkranz MS, Weinberg DV, Chou C, Whitcup SM; Dexamethasone DDS Phase II Study group: Dexamethasone posterior-segment drug delivery system in the treatment of macular edema resulting from uveitis or Irvine-Gass syndrome. Am J Ophthalmol 2009;147:10481054.

\$ Chang-Lin JE, Attar M, Acheampong AA, Robinson MR, Whitcup SM, Kuppermann BD, Welty D: Pharmacokinetics and pharmacodynamics of a sustained-release dexamethasone intravitreal implant. Invest Ophthalmol Vis Sci 2011;52:80-86. 